\title{
Eran Dorfman: Foundations of the everyday, shock, deferral, repetition
}

\author{
Rowman and Littlefield, London, 2014, 207 pp
}

\author{
Frank Chouraqui ${ }^{1}$
}

Published online: 3 May 2016

(C) The Author(s) 2016. This article is published with open access at Springerlink.com

The most influential and arguably the most robust characterization of modernity is famously provided by Foucault's Qu'est-ce que les Lumières? his text on Kant's idea of the Enlightenment. The essence of modernity, Foucault suggests, lies in its taking itself and its own place in history as an object of thought. Modernity is therefore a form of consciousness and a way of inhabiting the world which is historically determined. Further, this form of consciousness is characterized by a focus on eventfulness and on the decisive force of the present: It is our present that distinguishes us in the whole of the flow of history. In this line of thought, the world of the modern is a world of qualitative difference and of opportunity, of sequential, irreversible time, an exit from the ahistorical permanence of pre-modern times.

In his Foundations of the Everyday, Eran Dorfman seems to make the opposite argument: What characterizes late modernity, he argues, is its close entanglement with an experience of the everyday, of a time of repetition, habituation and permanence. However, staying content with such a prima facie contrast between Foucalt and Dorfman's views on modernity would miss the subtle and potent crux of Dorfman's argument: The fundamental place of the everyday and of the eventful for modernity are not mutually exclusive but interdependent. The object of Dorfman's analysis isn't eventlessness against eventfulness, but it is their coexistence and contemporaneity.

Dorfman's basic question could be formulated in this way: What is the experience of living in a world in which the everyday exists? But this immediately involves this other question: What is the existence of the everyday? The everyday's mode of existence, Dorfman suggests, is first and foremost conceptual. In

Frank Chouraqui

f.chouraqui@phil.leidenuniv.nl

1 Leiden University, Leiden, The Netherlands 
modernity, the everyday exists as a concept. Yet, as a concept, its existence relies on those (us, late moderns) who conceive of it, and who use it to describe the world, but also to guide our own actions and our lives. As a result, the everyday should be seen as a polarizing force for modern behavior. Here, Dorfman's kinship with Foucault surfaces: The everyday became an object of thought precisely against the new selfunderstanding of an epoch, modernity, which began regarding itself in contradistinction with the everyday of past history. Thus, the existence of the concept of the everyday requires precisely a modern condition of the type described by Foucault: one against which not only the everyday detaches itself by contrast, but even more, one in which the everyday can be invested with a certain form of (negative) valueas the repulsive pole of the modern experience.

A true engagement with this deep book therefore requires that we begin with the way it doubles out the concept of the everyday. Unfortunately, the doubling out is left implicit by Dorfman (leading to potential confusion) but let us try to clarify it here. Dorfman uses "everyday" in two senses, the first we might call "fantastical" and the other "modern." Let me explain how they interact. The fantastical sense of the everyday is fallacious, it is the idealized sense of a permanent present. It is one invested with negative connotations of passivity, boredom and connected with our most natural and animalistic dimensions. The modern sense is the correct one according to Dorfman: It is the process by which permanent time (the fantastical sense) leads into eventful time. Note that this makes the "correct" notion of the modern everyday deeply connected to a sense of ambiguity: Our everyday, Dorfman suggests, is spent neither in the fantastical everyday, nor in eventfulness, but in an in-between space structured by the repulsion towards the former and the projection towards the latter, a projection that endlessly fails (making any idealized notion of eventful time just as fantastical as the false idea of the everyday). This distinction involves a complex relation between the fantastical and the modern sense of the everyday: On the one hand, the fantastical everyday is false, but on the other hand it is necessary to understand the modern one. And its necessity is double:

First, its existence in the modern mental world has causal importance for our behavior. As the repulsive pole of our action, it structures our action: we will do anything to avoid the everyday. This is why such a concept of the everyday is literally fantastical: it is a fantasy, i.e.: a falsity that polarizes our behavior, it is false but not causally innocuous.

Secondly, the fantastical concept of the everyday is necessary to Dorfman himself. That is to say, it is necessary to whomever wishes to describe how the modern self's obsessive wish to avoid falling into the everyday of their fantasy thereby constitutes another, specifically modern experience of the everyday: our everyday is structured by our avoidance of the everyday. The account of the genuine notion of the everyday is premised on the false one. Dorfman thus comes to an analysis of the everyday no longer as this that the eventful [or as he sometimes simply says: "experience" (1)] rejects and escapes but precisely as this that connects the fear of boredom with the striving for newness: the modern everyday is the process by which the eventful rejects the permanent, and 
modernity becomes now refined not against Foucault, but alongside and beyond him. Modernity is the theater in which the interaction of two fantasies (that of permanent and eventful time) plays itself out in the soul of the modern subject. For Dorfman, like Kant and Foucault, sees modernity as the period in history where the way we spend our time is invested with value: if modernity regards itself as a historical opportunity, modern times are haunted with the fear of missing this opportunity or as we moderns call it: the fear of wasting our time.

So, if Dorfman's book indeed truly analyses the "foundations of the everyday," we must pay close attention to the meaning of "of": Dorfman is not investigating what makes the everyday what it is or what grounds it. Rather, he is drawing out how the everyday offers foundations for the modern existential predicament. He begins by declaring: "I propose the notion of foundation to capture the way the everyday functions. The everyday as a foundation is the background against which any significant activity occurs." (1-2, italic mine). So it seems that the everyday is the foundation of meaningfulness. Whether this foundation is conceptual (making the concept of the everyday necessary to the concept of meaning), existential (making the experience of the everyday necessary for the experience of meaning), or metaphysical (making the existence of repetitive time necessary to the existence of eventful time) is addressed-more or less directly-by appeal to the notions presented in the subtitle, those of "shock," "deferral" and "repetition." Together, these three operations characterize the everyday as the process through which the repulsion from the fantasized everyday throws the modern soul into a search for an equally fantastical "experience" or eventfulness.

By shock, Dorfman means what many readers are familiar with as "events": A shock is "every action or event that attempts to go 'outside' the global movement of the everyday." (3) It is a break (or an attempted break) in the fantasized linearity of the fantasized everyday. Naturally, this notion of shock involves a suspension of "the global movement of the everyday." It is this suspension Dorfman terms "deferral," i.e., the deferral of the fantasized everyday, a deferral which comes to characterize the modern everyday. In this context, repetition is the return of the "global movement of the everyday," its resumption after the interruption of shock and the deferral that followed. (3-4) This tri-partite structure is the core of the "late modern" experience of the everyday, now recognized as the experience of interruption. Although this proto-phenomenological account will probably invite controversy, let us remark immediately how quickly and directly it applies to the prosaic modern experience of stress, that is, of constant interruption. This is but one example of Dorfman's ability to surprise the reader with strikingly concrete implications of many of his more abstract discussions.

Thus, Dorfman's argument relies on six basic notions namely, the three explicit notions of shock, deferral, and repetition and the three implicit ones of "fantastical everyday," "modern" everyday and of a "fantastical eventfulness" named “experience. Nonetheless, Dorfman's argument is presented under a historical rather than systematic form. Chapters 1 and 2 investigate (and discard) the phenomenological contributions to the question of the everyday (in Husserl and Heidegger for Chapter 1, and in Merleau-Ponty for Chapter 2) before moving to 
Freud (Chapter 3), and to Benjamin (Chapter 4 and 5). Let me take them in turn, briefly.

Dorfman's engagement with phenomenology is designed to turn the notion of the everyday against it. The everyday, Dorfman contends, is an experience that phenomenology - the self-proclaimed science of experience-fails to account for. This is because directly or indirectly, phenomenology buys into the fantasy of authenticity, and therefore fails to acknowledge the ambiguous status of the experience of the everyday. Dorfman declares that "all three phenomenologists [Husserl, Heidegger and Merleau-Ponty] finally abandon the everyday in favor of a sphere of authenticity or full experience, a sphere in relation to which the everyday can be nothing but an inauthentic shadow." (90)

Dorfman begins by correctly locating the encounter of phenomenology with the everyday at the very beginning, that is to say, in the Husserlian theme of the phenomenological reduction. He notes two points of convergence between the Husserlian gesture and his own. First, the theme of the reduction involves an interruption - akin to Dorfman's own "shock" - which is known as "suspension" in the phenomenological language. Secondly, it involves a defiant stance towards the fantasized everyday (the "natural attitude" in Husserl's language). However, Dorfman points out that in Husserl, the (eidetic) reduction provides essences that come forward as "pure" events abstracted from their atmosphere of everydayness. This brings Husserlian phenomenology (Dorfman's Husserl is a transcendental idealist) very close to the fantasy of pure everydayness and pure eventfulness. All of this is all-too-pure for the everyday. As a result Dorfman finds that the core of his own view is precisely what phenomenology cannot account for: the fact that this fantasized everyday is precisely only a fantasy, and the fact that such essences are not truly events. Dorfman concludes that phenomenology cannot account for the constant projection of the fantasized everyday into a fantasized eventfulness, a projection that is the modern everyday itself, for this projection is neither authentic nor inauthentic, but is the continuity that moves from the fantastical inauthentic (pure everyday) to the fantastical authentic (pure eventfulness). Although it was introduced against Husserl, Dorfman's line of argument informs his reading of Heidegger too: Heideggerian authenticity is a fantastical eventfulness.

Even if one grants Dorfman's controversial account of Husserl and Heidegger, the reader is naturally compelled to look to Merleau-Ponty for a solution to the problem of the mutual exclusion of the authentic and the inauthentic in Heidegger and of the reduced attitude and the natural attitude in Husserl. After all, MerleauPonty's objection to Sartre takes its inspiration precisely from the need to account for the experience of ambiguity, from the realization that any "pure" experience is a contradiction and that the only authentic philosophy is a philosophy of inauthenticity. Precisely because Merleau-Ponty famously declared in the preface of the Phenomenology of Perception that "The most important lesson which the reduction teaches us it the impossibility of a complete reduction," one would be tempted to see in him the phenomenologist not of the opposition but of the continuity of the everyday and the event (a continuity Merleau-Ponty went on to call sedimentation) as well as the theorist of the continuity between the natural attitude and the reduced attitude. Although he implicitly recognizes that the case of Merleau-Ponty needs 
contending with seriously, Dorfman seems unfazed by the objection. He takes note of Merleau-Ponty's ambition of overcoming these oppositions with subtle accounts of continuity; but he argues that the Phenomenology of Perception fails to achieve it. On the contrary, he suggests, Merleau-Ponty is finally committed to a full, authentic notion of experience. This is because Dorfman's concept of the everyday poses, he contends, a set of requirements that exceeds those posed by MerleauPonty himself. While Merleau-Ponty's purpose was to establish the possibility of the appearance of a world, Dorfman's demand is for an account of a first-person experience in a historically determined situation: the psychological experience of the everyday in late modernity. Dorfman suggests that Merleau-Ponty's ontological route implies the loss of the psychological self within the undifferentiated ocean of being, and thereby amounts to a return to some sort of authenticity conceived as the harmony between the self and being as a whole (69). Phenomenology, Dorfman concludes, ignores the historical situation of the modern self alongside the personal character of the experience of ambiguity that supports the experience of the everyday.

The emphasis on the alleged lack of any first-person psychological dimension of the Merleau-Pontian notion of ambiguity throws Dorfman into the arms of Freud and his "notion of the psychic apparatus as a defensive mechanism in a hostile yet seductive everyday environment." (97) That is to say, Freud regards the interaction of the psychic apparatus and the everyday as structured exactly by the same three instances as Dorfman, namely, shock (hostility), deferral (defense) and repetition (seduction). Dorfman's analysis of Freud's evolution on the question of trauma and its implications for the question of deferral and the everyday is subtle, original and rich and leads into a fascinating parallel between Dorfman's own account of the ambiguity of the everyday and Freud's account of the ambiguous relation of the child and the adult (119-123). In the child's "pre-modern" everyday (120) Dorfman argues, the opposition of event, repetition and permanence is absent. This mode of being involves a certain mode of traumatizability, in which trauma leads to repetitive game-playing in the child, whereas it leads to repetitive compulsion in "modern" adults (122). Despite Dorfman's sympathies for the Freudian model, Freud misses the important existential point, namely that the type of the child and the type of the adult thus construed are mere fantasies themselves. The empirical subject indeed is a mixture of child and adult, and this leads Freud into "contradictions and entanglements" when he tries to account for this coexistence.

The last hope of finding a stable philosophy of ambiguity for Dorfman is in the work of Benjamin. Dorfman's careful investigation of Benjamin's analysis of mass production focuses first on the dialectic of mass-production (Chapter 4) and then on the aura (Chapter 5). The takeway there is that although Benjamin's idea that modernity (and especially industrialized modernity) involved a fundamental upset in the relations between material and auratic presence is correct, Benjamin did not go far enough in investigating how these two modes of presence could be reconfigured in late modernity towards a re-auratization of the everyday. According to Dorfman, we must recognize that auratic presence can be restored to the everyday: What becomes auraticized is precisely this late-modern striving to evade 
a fantastical repulsive pole of everydayness towards the attractive (and equally fantastical) pole of "experience." The final section of Chapter 5, in which Dorfman focuses on the work of artist Cindy Sherman, makes a delicious point about the selfunderstanding of modernity as a constantly failed effort at turning our very everyday existence onto icons. (173-181)

By now, it may be clear to the reader that Dorfman's book has a range, a depth of inspiration and a multilayered quality that forcefully demands our attention. It is a subtle investigation of our current predicament, one which solidly resists the doubleedged sword of romanticism and cynicism. I say "solidly," because the rejection of the alternative is grounded here at the deepest ontological level: The eventfulness which is the object of romanticism and the everyday which is the object of our cynicism are recognized as mere fantasies. But cultural analysis and an ontology of history are only two out of the four dimensions of Dorfman's contribution. The other two concern his work as a historian of philosophy and a literary and art critic. Although for reasons of space, I have only mentioned how Dorfman's analysis pours out of philosophy stricto sensu into Sherman's work, the reader will find elegant and compelling analyses of literary works by Michel Houellebecq and Margerite Duras, of artworks by Bill Viola, and of Leni Riefenstahl's famous and ominous Triumph of the Will (subtly and correctly relocating Nazism within the romantic worldview) among others.

Of course, such a kaleidoscopic range of interests runs the risk of dazzling the reader. It is a risk increased by Dorfman's oft-ambiguous formulations (two of which have been alluded to: The "foundations of the everyday" are not what founds the everyday but what the everyday founds, and the analysis of the everyday is not an analysis of what the everyday is, but an analysis of what a world in which the concept of the everyday exists should look like). But this didactic lack should only put off the readers deaf to Dorfman's invitation to think alongside him, and not after him. Part of this invitation, it may be apparent by now, is a promise thrown into the unknown: Dorfman's book is best read as a negative preparation to a more positive elaboration of the ontology involved in his concept of the everyday as ambiguity. Dorfman's unrelenting challenge issued to the canonical Continental tradition to think through ambiguity without collapsing into any fantasized notion of authenticity allows him to make his point negatively, but it also distracts from the specifically philosophical intention of the book: the project of building an ontology of ambiguity.

It is also there, in his engagement with the authors that Dorfman's analysis lends itself to fiercer criticisms: If I am right to see Dorfman's book as an appeal to embed the late-modern condition into an ontology of ambiguity, the criticism addressed in Chapters 1 and 2 to phenomenology might require a second look-Dorfman maintains his complaint that this phenomenological ontology is either too impersonal or too a-historical. One may wish to probe whether this objections is not self-defeating: Indeed, isn't the objection itself resting on some sense of disconnection between the modern and the non-modern, the individual and the impersonal, and on a strong, implausible (if not inconceivable) and indeed, fantasized concept of the event called late modernity as a clean break which should preclude the very ambiguity sought-after? The great merit of Dorfman's book is to 
be able to account for qualitative-existential differences (such as the difference in the subjective experience of late modernity) without any breaks: For this experience is precisely that of a rearrangement of six elements that remain constant. It will be for the reader to decide whether Dorfman truly breaks away from phenomenology or furthers its work. In any case, the unprecedentedly sympathetic ear he lends to the endless little sufferings of the late-modern condition makes his book an important contribution to our self-understanding, and to the urgent project of cultural therapy.

Open Access This article is distributed under the terms of the Creative Commons Attribution 4.0 International License (http://creativecommons.org/licenses/by/4.0/), which permits unrestricted use, distribution, and reproduction in any medium, provided you give appropriate credit to the original author(s) and the source, provide a link to the Creative Commons license, and indicate if changes were made. 